\title{
Supplementary Materials for A Step-by-Step Process-Induced Unidirectional Oriented Water Wire in the Nanotube
}

\author{
Le Jin, ${ }^{1}$ Depeng Zhang, ${ }^{1}$ Yu Zhu, ${ }^{1}$ Xinrui Yang,,${ }^{1,2}$ Yi Gao, ${ }^{3}$ and Zhigang Wang ${ }^{* 1}$ \\ ${ }^{1}$ Institute of Atomic and Molecular Physics, Jilin University, Changchun 130012, China \\ ${ }^{2}$ College of Physics, Jilin University, Changchun 130012, China \\ ${ }^{3}$ Shanghai Advanced Research Institute, Chinese Academy of Sciences, Shanghai 201210, China.
}

Corresponding author: wangzg@jlu.edu.cn (Z.W.)

Part 1. Reliability of the used classical and quantum methods

Part 2. Statistics on the dipole moments of water chains

Part 3. Statistics on average persistent time of dipole alignment for water chains

Part 4. Comparison of the average rotation time of water molecules inside and at both ends of the water chain

Part 5. The dynamic properties of water chain in chiral CNTs

Part 6. The dynamic properties of "heavy"-water chain in $(6,6)$ CNT

Part 7. The $\mathrm{O}-\mathrm{H}$ stretching varies along the process

Part 8. The flipping processes of water dimer and trimer chains

Figure S1. Snapshots of trajectories for the typical molecular orientation of the water pentamer chain confined in $(6,6)$ CNT. (a) The change of dipole angle for each water molecule. (b) The flipping process of water pentamer chain. (c) Comparison of the rotation time of each water molecule for the pentamer chain.

Figure S2. Snapshots of trajectories for the typical molecular orientation of water tetramer chain confined in chiral $(8,4)$ CNT. (a) The change of dipole angle for each water molecule in the chain. (b) The flipping process of water tetramer chain. (c) Comparison of the rotation time of each water molecule for the tetramer chain.

Figure S3. The atomic numbers of water dimer.

Figure S4. Comparison of the rotation time of each water molecule for the tetramer chain. The chains consist of (a) $4 \mathrm{H}_{2} \mathrm{O}$ and (b) $4 \mathrm{D}_{2} \mathrm{O}$ molecules. 
Figure S5. The $\mathrm{O}-\mathrm{H}$ stretching varies along the flipping process of water chains. (a) Structures of water dimer, trimer and tetramer chains. The $\mathrm{O}-\mathrm{H}$ stretching varies in water (b) dimer, (c) trimer and (d) tetramer chains. The $\mathrm{O}-\mathrm{H}$ bond lengths of water chains were distinguished by different colors. The solid and dashed lines were the change of $\mathrm{O}-\mathrm{H}$ bonds that participated and did not participate in the flip process, respectively.

Figure S6. The flipping process for the water dimer chain in CNT.

Figure S7. The flipping process for the water trimer chain in CNT.

Figure S8. The step-by-step flipping process of the water chain. The water dimer and trimer chains were shown in left and right column, respectively.

Table S1. Comparison of the stable structures for water dimer confined in different CNTs.

Table S2. The coordinates of the water chain consisting of two water molecules in the CNT corresponding to the three extreme points on the potential energy surface.

Table S3. The coordinates of the water chain consisting of three water molecules in the CNT corresponding to the five extreme points on the potential energy surface.

Table S4. The coordinates of the water chain consisting of four water molecules in the CNT corresponding to the seven extreme points on the potential energy surface.

Table S5. The coordinates of the CNT.

References 


\section{Part 1. Reliability of the used classical and quantum methods}

In this work, by means of MD simulations and first-principles calculations, the flipping process of the confined water chain was mainly revealed from the two aspects of dynamic properties and reaction path, respectively. On the one hand, for the firstprinciples calculations, we carried out the empirical-dispersion-corrected hybrid Perdew-Burke-Ernzerhof (PBE0-D3) method of density functional theory. PBE0-D3 is suitable to describe the $\mathrm{H}$-bonding interaction between water molecules, which makes it widely used in the study of the cluster, H-bond network, adsorption, interface, infrared spectrum, etc. ${ }^{1-5}$ Therefore, to find the flipping process of water chain confined in CNT, this method was employed to search transition states and traced the reaction path in our work. On the other hand, the empirical force fields methods are widely used in the study of confined water. ${ }^{6-8}$ For our MD simulations, the OPLS-AA force field and TIP3P water model were widely used for the study of water properties. ${ }^{9-10}$ Based on the above, the methods in our work were suitable and the reliability of the results was guaranteed.

\section{Part 2. Statistics on the dipole moments of water chains}

To count the flip of the dipole of different water chain, the total dipole moment was calculated according to the sum of all the dipole vectors of the water molecules in the chain. Here, the length of the dipole vector of one water was set as one unit to describe the relative dipole length of the water chain. Therefore, the total dipole vector of a water chain was obtained. The change of its direction and the change of the projection of its relative length on the axis during the simulation time were confirmed, as shown in Figure 1(c). Based on this approach, we have not only tracked the rotation process of a single water molecule, but also realized the judgment of the total dipole direction change of the water chain with different lengths during the simulation.

\section{Part 3. Statistics on average persistent time of dipole alignment for water chains}

The water chain is continuous. As we all know, for a water chain, the distance between $\mathrm{O}-\mathrm{O}$ atoms of adjacent water molecules is not more than $3.5 \AA$. Here, it is determined whether the water chain is broken according to the distance between oxygen and oxygen atoms in different water molecules. Taking pentamer as an example, the maximum distance between two oxygen atoms in water molecules at both ends of the water chain is $14 \AA(3.5 \AA \times 4)$. If the distance between the oxygen atoms of any two water molecules in the water chain is greater than $14 \AA$, the water chain is considered broken, otherwise it is continuous.

For each frame of the molecular dynamics simulation, the total dipole moment was calculated according to the sum of all the dipole moments of the water molecules in the chain. If the dipole moment of the water chain is positive, the dipole orientation of the water chain is called upward. If the dipole moment of water chain is negative, the dipole orientation is called downward.

The duration $t_{u p}$ of each upward dipole orientation of the water chain was counted. We recorded the number of times $n_{u p}$ that the dipole appears upward. Similarly, for the number and duration of the dipole-down water chain can also be obtained.

Based on the above analysis, the average persistent time of dipole alignment for the water chain can be expressed as $\frac{\sum_{i}^{n_{u p}} t_{u p, i}+\sum_{i}^{n_{\text {down }}} t_{\text {down }, i}}{n_{u p}+n_{\text {down }}}$. 


\section{Part 4. Comparison of the average rotation time of water molecules inside and at both ends of the water chain}

The frames when the water chain remained continuous in the simulation trajectory were counted. Because the molecular dynamics simulations are carried out in NVT ensemble with periodic condition, the water chain may be broken and reconnected. This causes the position of each water molecule in the chain to change. Here, according to the coordinates of $\mathrm{O}$ atoms to locate water molecules, determine whether they are at both ends of the water chain or inside the water chain. Then, the statistics on the dipole angle of each water molecule in the chain were performed. The time $t_{i}$ of each water molecule rotation and the number of rotations $n$ are obtained. Further, the average rotation duration $\frac{\sum_{i}^{n} t_{i}}{n}$ of each water molecule in the chain was got.

\section{Part 5. The dynamic properties of water chain in chiral CNTs}

At present, there are few studies on water transport in chiral carbon nanotubes (CNTs). It is commonly assumed that the behavior of water properties in CNTs depends on the diameter of CNTs, rather than their chirality. ${ }^{11}$ In recent years, several studies pointed out that the flux of water is affected by the chirality of CNTs. The water flux in armchair CNTs, chiral CNTs and zigzag CNTs gradually decreases. And the chiral effect decreases with the increase of CNT diameter. ${ }^{12}$ It was also reported that pumping water can be achieved by rotating chiral CNTs. And the water flux has a linear relationship with the radius when the length of the CNT is much larger than the radius. ${ }^{13}$ So far, the effect of chiral CNTs on the orientation of water chain is still unclear, which can be a very valuable subject and will be worthy of long-term efforts in the future.

To estimate the chiral effect of CNTs, we tested the flipping process of water chain in $(8,4),(9,3)$ and $(11,0)$ CNTs. The diameters of three CNTs are $8.13 \AA, 8.33 \AA$ and $8.37 \AA$, which are close to that of $(6,6)$ CNT $(8.20 \AA)$. The dynamic simulations and the calculations of stable structures were completed to respond to the reviewer's comment and the used methods are consistent with that in our paper.

MD simulations show that the average time between the flipping intervals of water chains in the three CNTs were about 19 picosecond (ps), 15 ps and 8 ps, respectively. As the diameter increases, the average time becomes shorter. It was also found that the time of water chain in the chiral $(8,4)$ CNT was closest to that in armchair $(6,6)$ CNT (about $21 \mathrm{ps}$ ), which is due to the similar diameter. Besides, the first-principles calculations show that the stable structures of water chains confined in $(8,4),(9,3)$ and $(11,0)$ CNTs were similar.

Then, using $(8,4) \mathrm{CNT}$, we performed MD simulations to understanding the flip property of water chain with increase the number of water molecules. The average time between the flipping intervals of the water chain was about 5 ps for trimer, 19 ps for tetramer and 58 ps for pentamer, which are very close to the time in $(6,6)$ CNTs $(6 \mathrm{ps,}$ $21 \mathrm{ps}, 69 \mathrm{ps}$, respectively). With the increase of the number of water molecules, the average time between flipping intervals of water chains presents similar order of magnitude changes as in $(6,6) \mathrm{CNT}$. Taking the water tetramer as an example, the snapshots of the trajectories for the typical orientation of water molecules were shown in Figure S2. It can be seen that the flipping process is still step-by-step and the water molecules at both ends of the chain rotated more easily than that of the internal water 
molecules. These findings were all qualitatively consistent with the properties of water chain in armchair $(6,6)$ CNTs.

Further, the stable structures of water chain in different CNTs were obtained by using first-principles calculations. Taking water dimer as an example, to compare the structural changes intuitively, we gave the bond lengths, bond angles and dihedral angle of water dimers in different CNTs (see Figure S3 and Table. S1 for details). From $(6,6)$ CNT to other CNTs, the structure of confined water dimer changed slightly.

\section{Part 6. The dynamic properties of "heavy"-water chain in $(6,6)$ CNT}

When the water molecules change from "light"-water $\left(\mathrm{H}_{2} \mathrm{O}\right)$ to "heavy"-water $\left(\mathrm{D}_{2} \mathrm{O}\right)$, the change is just the number of neutrons. The electronic structure of water molecules has not changed. For the potential energy surfaces, it is mainly related to electrons, but not neutrons. Therefore, deuterate or "heavy"-water, the energy barrier of flipping process should remain the same as before.

To explore the dynamic properties of "heavy" water, we performed MD simulations using four $\mathrm{D}_{2} \mathrm{O}$ molecules in $(6,6) \mathrm{CNT}$. The parameters setting and analytical method were the same as those for the simulation on $\mathrm{H}_{2} \mathrm{O}$ molecules in $(6,6) \mathrm{CNT}$. As shown in Figure $\mathrm{S} 4$, the average rotation time for end $\mathrm{D}_{2} \mathrm{O}$ molecules takes only few picoseconds, and that for the middle $\mathrm{D}_{2} \mathrm{O}$ molecule took up to tens of picoseconds, which demonstrated that the water molecules at both ends of the chain rotated more easily than that of the internal water molecules. This is qualitatively consistent with four $\mathrm{H}_{2} \mathrm{O}$ molecules in $(6,6) \mathrm{CNT}$. At the same time, we also notice that the rotation time of each water molecule for the four $\mathrm{D}_{2} \mathrm{O}$ molecules chain is greater than each water molecule for the four $\mathrm{H}_{2} \mathrm{O}$ molecules chain. In addition, the persistent time of dipole alignment for water tetramer chains was calculated. The results show that the average time between the flipping intervals of the four $\mathrm{D}_{2} \mathrm{O}$ molecules was about $30 \mathrm{ps}$, which was longer than that of four $\mathrm{H}_{2} \mathrm{O}$ molecules (about $21 \mathrm{ps)}$ ). This indicated that the $\mathrm{H}_{2} \mathrm{O}$ is easier to maintain the unidirectional single-file water flow than $\mathrm{D}_{2} \mathrm{O}$, which is consistent with previous reports. ${ }^{14-15}$ These are attributed to $\mathrm{D}_{2} \mathrm{O}$ having two more neutrons than $\mathrm{H}_{2} \mathrm{O}$, making the mass of $\mathrm{D}_{2} \mathrm{O}$ is larger than that of $\mathrm{H}_{2} \mathrm{O}$, resulting in the water chain with four $\mathrm{D}_{2} \mathrm{O}$ molecules flips slower.

\section{Part 7. The $\mathrm{O}-\mathrm{H}$ stretching varies along the process}

At first, to distinguish different $\mathrm{O}-\mathrm{H}$ bonds clearly, we labeled the related atoms. As shown in Figure S5, the molecules in the water chain were marked as $1,2,3, \ldots$ on the $\mathrm{O}$ atom in order from bottom to top. Then, the two hydrogen atoms of each molecules were marked as 1 and 2, respectively. Therefore, the two $\mathrm{O}-\mathrm{H}$ bonds of this molecule can be labeled as $\mathrm{O}-\mathrm{H}_{-2-1}$ and $\mathrm{O}-\mathrm{H}_{-2-2}$, where the first number represents oxygen atom (i.e., the number of this molecule) and the second number represents hydrogen atom.

By analyzing the structures on the reaction path, the variations of all $\mathrm{O}-\mathrm{H}$ bonds lengths along the flipping process of water dimer, trimer and tetramer chains were obtained. Taking water tetramer chain as an example (Figure S5 (d)), the lengths of $\mathrm{O}-\mathrm{H}$ bonds that did not participate in the breaking and generating of hydrogen bonds (H-bonds) were 1.00-1.02 $\AA$ (dashed lines). However, the lengths of the $\mathrm{O}-\mathrm{H}$ bond participated in $\mathrm{H}$-bonds can reach to $1.07 \AA$ (solid lines). The formation of $\mathrm{H}$-bond stretched the corresponding $\mathrm{O}-\mathrm{H}$ bond and the magnitude of the changes were $10^{-2} \AA$. This bond property is also applied to that of water dimer and trimer chain. 


\section{Part 8. The flipping processes of water dimer and trimer chains}

For the water dimer chain as seen in Figure S6, the initial orientation of H-bond in the water chain is upward. From reactant to transition state, the H-bond is broken. From transition state to product, the $\mathrm{H}$-bond is rebuilt, and its orientation moves downward.

The detailed flipping process of water trimer is given in Figure S7. It shows the change of the H-bonds orientations when the water chain flips. The five structures correspond to the five extreme points on the PES. In detail, the initial orientations of all $\mathrm{H}$-bonds are upward. Then, from reactant to intermediate, the H-bond of the lower two water molecules is broken. When the $\mathrm{H}$-bond is rebuilt, its orientation moves downward. However, there is no change for the $\mathrm{H}$-bond orientation of the upper two water molecules. While from intermediate to product, the $\mathrm{H}$-bond between the upper two water molecules is broken and rebuilt, and the orientation moves downward. For the lower two water molecules, the H-bond orientation is still downward. Therefore, the complete flipping process of the water chain is demonstrated. 


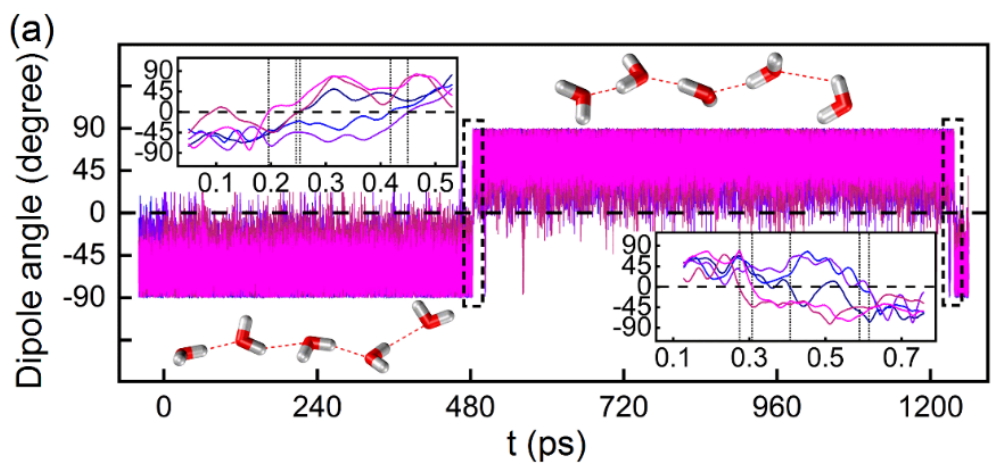

(b)

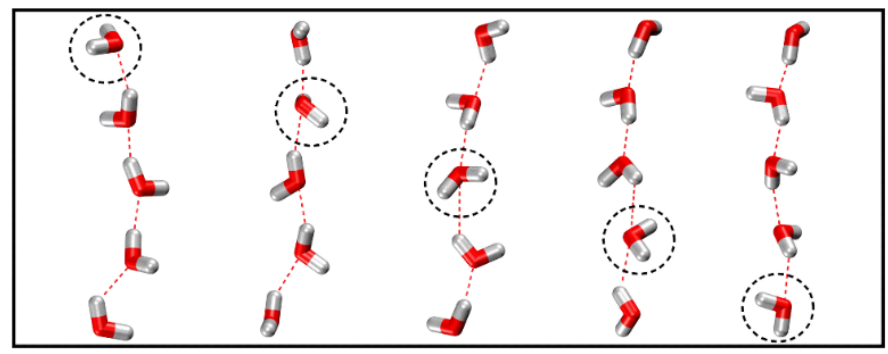

(c)

3.240

ำ

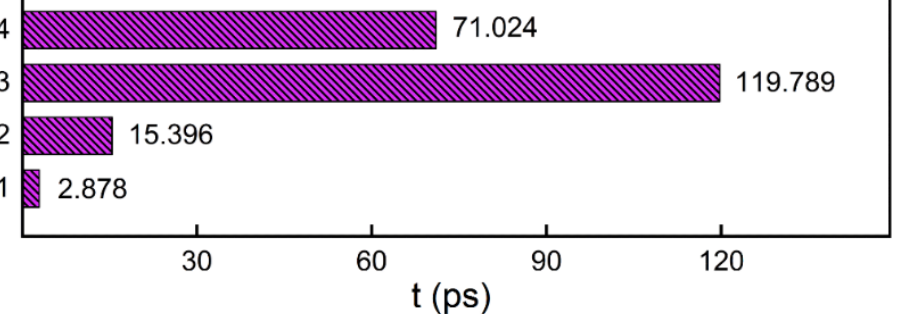

Figure S1. Snapshots of trajectories for the typical molecular orientation of the water pentamer chain confined in $(6,6) \mathrm{CNT}$. (a) Change of dipole angle for each water molecule. (b) Flipping process of water pentamer chain. (c) Comparison of the rotation time of each water molecule for the pentamer chain. 

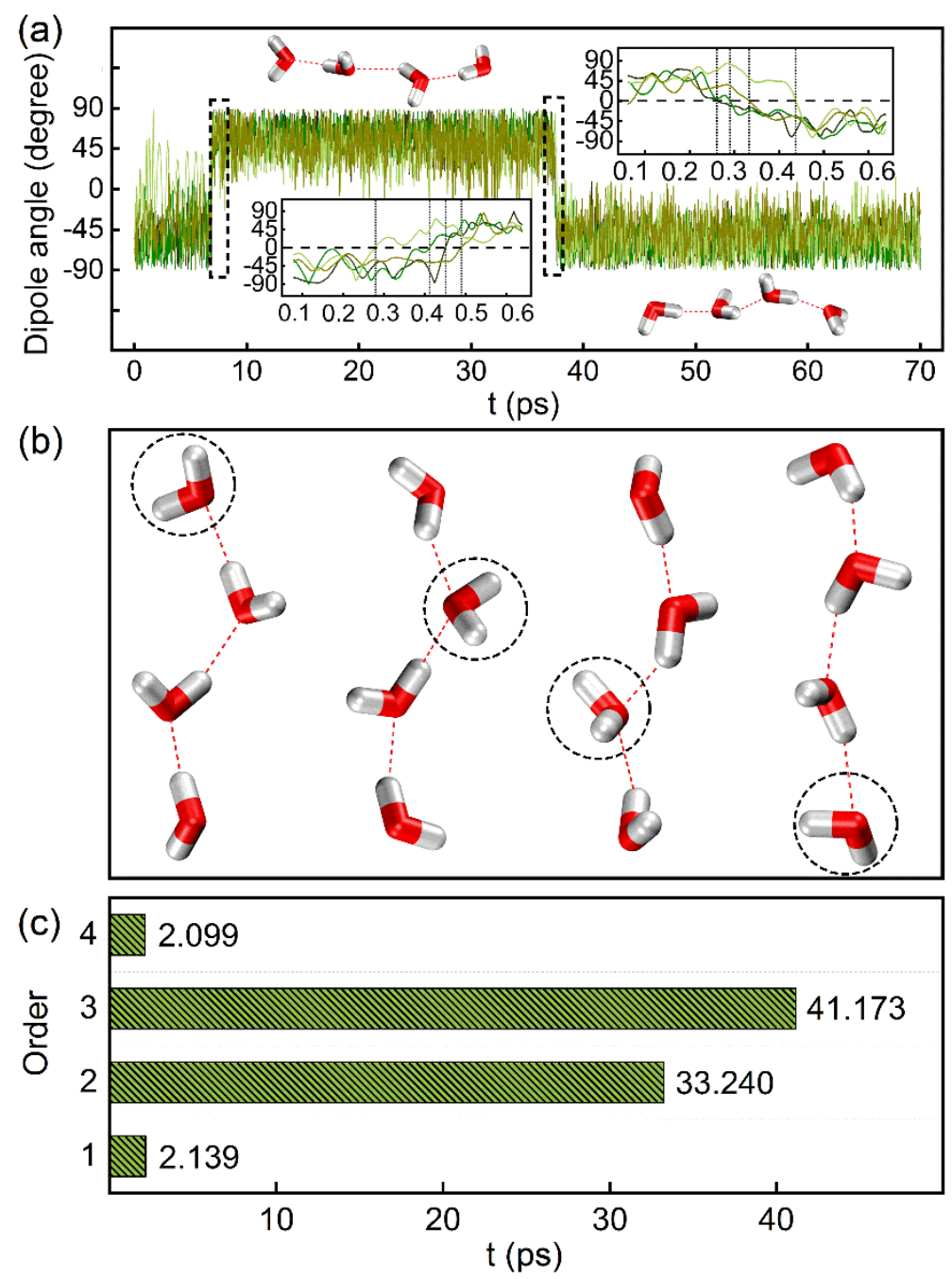

Figure S2. Snapshots of trajectories for the typical molecular orientation of water tetramer chain confined in chiral $(8,4) \mathrm{CNT}$. (a) Change of dipole angle for each water molecule in the chain. (b) Flipping process of water tetramer chain. (c) Comparison of the rotation time of each water molecule for the tetramer chain. 


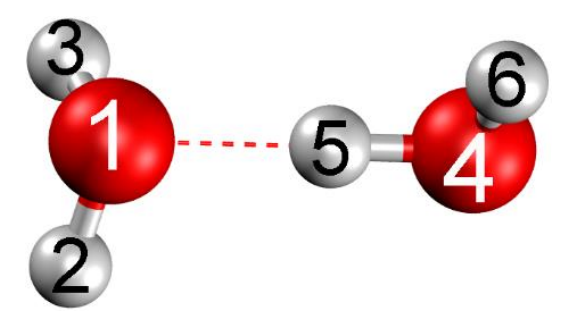

Figure S3. The atomic numbers of water dimer.

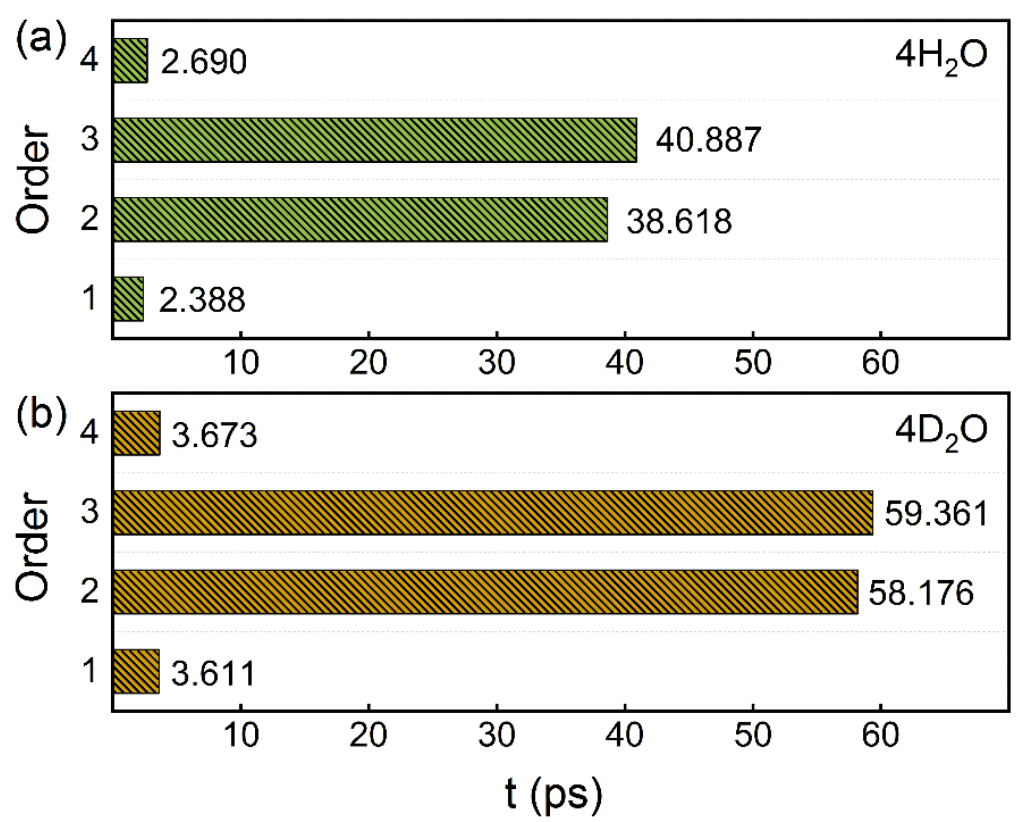

Figure S4. Comparison of the rotation time of each water molecule for the tetramer chain. The chains consist of (a) $4 \mathrm{H}_{2} \mathrm{O}$ and (b) $4 \mathrm{D}_{2} \mathrm{O}$ molecules. 

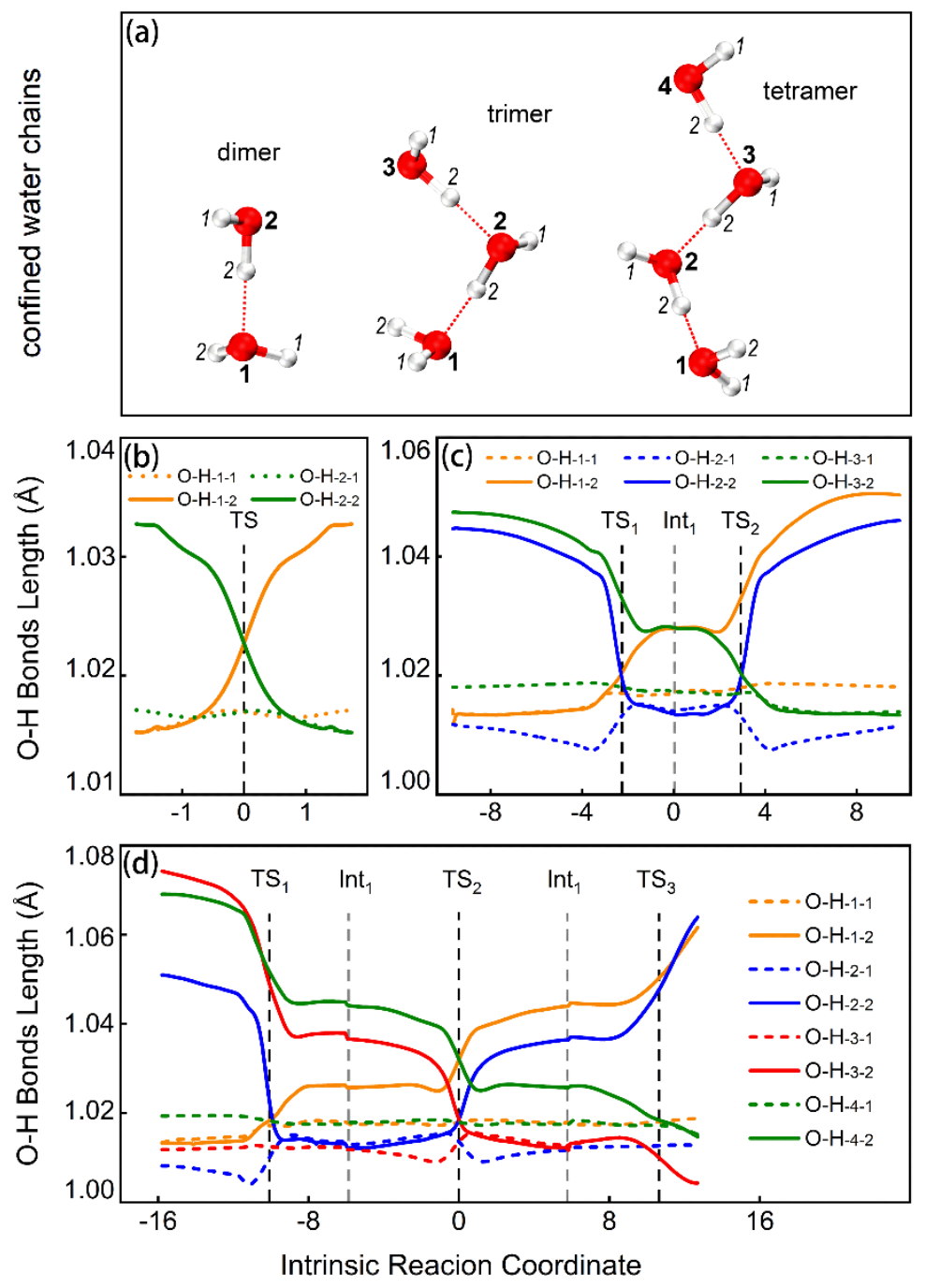

Figure S5. The $\mathrm{O}-\mathrm{H}$ stretching varies along the flipping process of water chains. (a) Structures of water dimer, trimer and tetramer chains. The $\mathrm{O}-\mathrm{H}$ stretching varies in water (b) dimer, (c) trimer and (d) tetramer chains. The $\mathrm{O}-\mathrm{H}$ bond lengths of water chains were distinguished by different colors. The solid and dashed lines were the change of $\mathrm{O}-\mathrm{H}$ bonds that participated and did not participate in the flip process, respectively. 


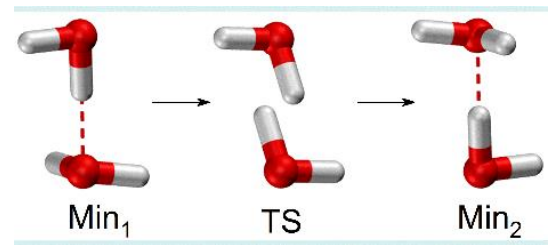

Figure S6. The flipping process for the water dimer chain in CNT.

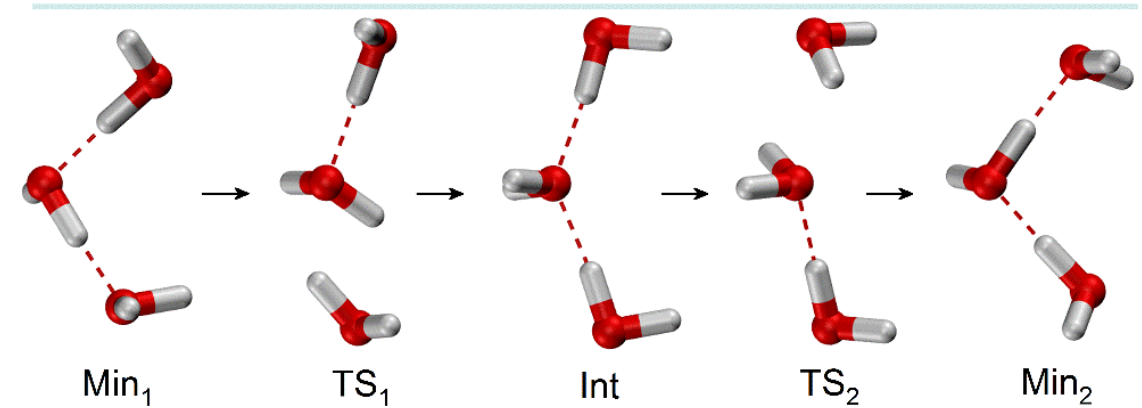

Figure S7. The flipping process for the water trimer chain in CNT.

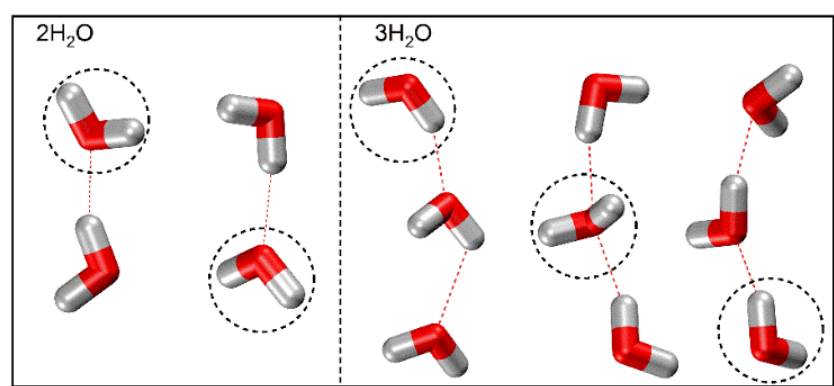

Figure S8. The step-by-step flipping process of the water chain. The water dimer and the water trimer chains were shown in left and right column, respectively. 
Table S1. Comparison of the stable structures for water dimer confined in different CNTs.

\begin{tabular}{|c|c|c|c|c|c|}
\hline & Parameters & $(8,4) \mathrm{CNT}$ & $(6,6) \mathrm{CNT}$ & $(9,3) \mathrm{CNT}$ & $(11,0) \mathrm{CNT}$ \\
\hline \multirow{2}{*}{ H-bond } & Length (15) & $1.59 \AA$ & $1.59 \AA$ & $1.59 \AA$ & $1.59 \AA$ \\
\hline & Angle (541) & $1.12^{\circ}$ & $0.78^{\circ}$ & $0.63^{\circ}$ & $0.74^{\circ}$ \\
\hline \multirow{4}{*}{$\begin{array}{c}\mathrm{O}-\mathrm{H} \\
\text { bonds }\end{array}$} & Length (12) & $1.02 \AA$ & $1.01 \AA$ & $1.01 \AA$ & $1.01 \AA$ \\
\hline & Length (13) & $1.01 \AA$ & $1.02 \AA$ & $1.01 \AA$ & $1.02 \AA$ \\
\hline & Length (45) & $1.03 \AA$ & $1.03 \AA$ & $1.03 \AA$ & $1.03 \AA$ \\
\hline & Length (46) & $1.02 \AA$ & $1.02 \AA$ & $1.02 \AA$ & $1.02 \AA$ \\
\hline $\mathrm{H}-\mathrm{O}-\mathrm{H}$ & Angle (213) & $98.61^{\circ}$ & $98.59^{\circ}$ & $98.54^{\circ}$ & $98.59^{\circ}$ \\
\hline Angle & Angle (516) & $19.41^{\circ}$ & $19.55^{\circ}$ & $19.62^{\circ}$ & $19.49^{\circ}$ \\
\hline \multirow{2}{*}{ Other } & Dihedral (2146) & $-142.42^{\circ}$ & $-142.26^{\circ}$ & $-144.77^{\circ}$ & -137.54 \\
\hline & Length (14) & $2.62 \AA$ & $2.62 \AA$ & $2.62 \AA$ & $2.62 \AA$ \\
\hline
\end{tabular}

* Length (15) represents the length between $\mathrm{O}_{1}$ atom and $\mathrm{O}_{5}$ atom in Figure $\mathrm{S} 3$, which is the same way to represent angles, dihedral angles.

Table S2. The coordinates of the water chain consisting of two water molecules in the CNT corresponding to the three extreme points on the potential energy surface.

\begin{tabular}{rrrrrr}
\hline & Number & Atom & $x(\AA)$ & $y(\AA)$ & $z(\AA)$ \\
\hline & 1 & $\mathbf{O}$ & $\mathbf{- 0 . 0 6 6}$ & $\mathbf{0 . 5 9 6}$ & $\mathbf{- 1 . 1 4 7}$ \\
Start Structure & 2 & H & $\mathbf{0 . 7 5 3}$ & $\mathbf{1 . 1 9 1}$ & $\mathbf{- 1 . 2 3 1}$ \\
& 3 & H & $\mathbf{- 0 . 7 6 4}$ & $\mathbf{1 . 3 1 9}$ & $\mathbf{- 1 . 0 0 1}$ \\
& 4 & $\mathbf{O}$ & $\mathbf{0 . 2 0 0}$ & $\mathbf{- 0 . 5 4 0}$ & $\mathbf{1 . 2 0 4}$ \\
& 5 & H & $\mathbf{0 . 1 1 0}$ & $\mathbf{- 0 . 1 1 4}$ & $\mathbf{0 . 2 6 8}$ \\
TS Structure & 6 & H & $\mathbf{- 0 . 5 1 2}$ & $\mathbf{- 1 . 2 5 9}$ & $\mathbf{1 . 0 9 7}$ \\
\hline & 1 & $\mathbf{O}$ & $\mathbf{- 0 . 1 1 3}$ & $\mathbf{0 . 5 3 5}$ & $\mathbf{- 1 . 1 5 4}$ \\
& 2 & H & $\mathbf{0 . 6 2 7}$ & $\mathbf{1 . 2 3 2}$ & $\mathbf{- 1 . 1 7 2}$ \\
& 3 & H & $\mathbf{- 0 . 4 6 4}$ & $\mathbf{0 . 7 2 7}$ & $\mathbf{- 0 . 2 1 3}$ \\
& 4 & $\mathbf{O}$ & $\mathbf{0 . 1 1 3}$ & $\mathbf{- 0 . 5 3 7}$ & $\mathbf{1 . 1 3 7}$ \\
End Structure & 5 & H & $\mathbf{0 . 4 6 4}$ & $\mathbf{- 0 . 7 2 9}$ & $\mathbf{0 . 1 9 6}$ \\
& 6 & H & $\mathbf{- 0 . 6 2 7}$ & $\mathbf{- 1 . 2 3 5}$ & $\mathbf{1 . 1 5 6}$ \\
\hline & 1 & $\mathbf{O}$ & $\mathbf{- 0 . 2 0 1}$ & $\mathbf{0 . 5 4 1}$ & $\mathbf{- 1 . 2 0 5}$ \\
& 2 & H & $\mathbf{0 . 5 1 1}$ & $\mathbf{1 . 2 5 9}$ & $\mathbf{- 1 . 0 9 8}$ \\
& 3 & H & $\mathbf{- 0 . 1 1 1}$ & $\mathbf{0 . 1 1 4}$ & $\mathbf{- 0 . 2 6 9}$ \\
& 4 & O & $\mathbf{0 . 0 6 5}$ & $\mathbf{- 0 . 5 9 6}$ & $\mathbf{1 . 1 4 6}$ \\
& 5 & H & $\mathbf{0 . 7 6 3}$ & $\mathbf{- 1 . 3 1 9}$ & $\mathbf{0 . 9 9 9}$ \\
& 6 & H & $\mathbf{- 0 . 7 5 4}$ & $\mathbf{- 1 . 1 9 1}$ & $\mathbf{1 . 2 3 0}$ \\
\hline
\end{tabular}


Table S3. The coordinates of the water chain consisting of three water molecules in the CNT corresponding to the five extreme points on the potential energy surface.

\begin{tabular}{|c|c|c|c|c|c|}
\hline & Number & Atom & $x(\AA)$ & $\mathrm{y}(\AA)$ & $\mathrm{z}(\AA)$ \\
\hline \multirow{9}{*}{ Start Structure } & 1 & O & 1.054 & -0.296 & 2.944 \\
\hline & 2 & H & 0.392 & -0.662 & 3.625 \\
\hline & 3 & $\mathbf{H}$ & 0.361 & 0.042 & 2.235 \\
\hline & 4 & $\mathbf{O}$ & -0.598 & 0.479 & 1.176 \\
\hline & 5 & H & -0.208 & 0.035 & 0.315 \\
\hline & 6 & $\mathbf{H}$ & -0.351 & 1.444 & 1.001 \\
\hline & 7 & $\mathbf{O}$ & 0.384 & -0.619 & -0.870 \\
\hline & 8 & $\mathbf{H}$ & 1.368 & -0.789 & -0.694 \\
\hline & 9 & $\mathbf{H}$ & 0.044 & -1.572 & -0.869 \\
\hline \multirow{9}{*}{$\mathrm{TS}_{1}$ Structure } & 1 & $\mathbf{O}$ & 0.988 & 0.076 & 3.618 \\
\hline & 2 & $\mathbf{H}$ & 0.372 & -0.721 & 3.767 \\
\hline & 3 & $\mathbf{H}$ & 0.712 & 0.286 & 2.646 \\
\hline & 4 & $\mathbf{O}$ & 0.302 & 0.616 & 1.135 \\
\hline & 5 & $\mathbf{H}$ & 1.157 & 0.584 & 0.584 \\
\hline & 6 & $\mathbf{H}$ & 0.125 & 1.614 & 1.104 \\
\hline & 7 & $\mathbf{O}$ & 0.520 & -0.262 & -1.280 \\
\hline & 8 & $\mathbf{H}$ & 0.625 & -1.271 & -1.206 \\
\hline & 9 & $\mathbf{H}$ & -0.163 & -0.134 & -0.532 \\
\hline \multirow{9}{*}{ Int Structure } & 1 & $\mathbf{O}$ & 0.627 & 0.309 & 3.450 \\
\hline & 2 & H & 1.066 & -0.602 & 3.343 \\
\hline & 3 & $\mathbf{H}$ & 0.375 & 0.461 & 2.465 \\
\hline & 4 & $\mathbf{O}$ & -0.052 & 0.811 & 0.919 \\
\hline & 5 & $\mathbf{H}$ & 0.163 & 1.799 & 0.858 \\
\hline & 6 & $\mathbf{H}$ & -1.064 & 0.861 & 0.893 \\
\hline & 7 & $\mathbf{O}$ & 0.791 & -0.092 & -1.445 \\
\hline & 8 & $\mathbf{H}$ & 0.725 & -1.094 & -1.280 \\
\hline & 9 & $\mathbf{H}$ & 0.482 & 0.225 & -0.517 \\
\hline \multirow{9}{*}{$\mathrm{TS}_{2}$ Structure } & 1 & $\mathbf{O}$ & 0.683 & 0.445 & 3.408 \\
\hline & 2 & $\mathbf{H}$ & 1.235 & -0.406 & 3.476 \\
\hline & 3 & $\mathbf{H}$ & 0.005 & 0.120 & 2.716 \\
\hline & 4 & $\mathbf{O}$ & 0.064 & 0.674 & 0.914 \\
\hline & 5 & $\mathbf{H}$ & 0.846 & 1.125 & 1.383 \\
\hline & 6 & $\mathbf{H}$ & -0.541 & 1.479 & 0.796 \\
\hline & 7 & $\mathbf{O}$ & 0.909 & 0.016 & -1.489 \\
\hline & 8 & $\mathbf{H}$ & 0.494 & -0.912 & -1.535 \\
\hline & 9 & $\mathbf{H}$ & 0.579 & 0.271 & -0.546 \\
\hline \multirow{9}{*}{ End Structure } & 1 & $\mathbf{O}$ & 0.769 & -0.129 & 2.906 \\
\hline & 2 & $\mathbf{H}$ & 1.711 & 0.123 & 2.632 \\
\hline & 3 & H & 0.876 & -1.136 & 2.953 \\
\hline & 4 & $\mathbf{O}$ & -0.646 & 0.300 & 0.869 \\
\hline & 5 & $\mathbf{H}$ & -0.089 & 0.125 & 1.737 \\
\hline & 6 & H & -0.761 & 1.303 & 0.936 \\
\hline & 7 & $\mathbf{O}$ & 1.071 & -0.026 & -0.961 \\
\hline & 8 & $\mathbf{H}$ & 0.534 & -0.641 & -1.569 \\
\hline & 9 & $\mathbf{H}$ & 0.343 & 0.118 & -0.218 \\
\hline
\end{tabular}


Table S4. The coordinates of the water chain consisting of four water molecules in the CNT corresponding to the seven extreme points on the potential energy surface.

\begin{tabular}{|c|c|c|c|c|c|}
\hline & Number & Atom & $\mathrm{x}(\AA)$ & $\mathrm{y}(\AA)$ & $\mathrm{z}(\AA)$ \\
\hline \multirow{12}{*}{ Start Structure } & 1 & $\mathbf{O}$ & -0.810 & -0.095 & 0.281 \\
\hline & 2 & $\mathbf{H}$ & $-\mathbf{- 0 . 8 3 0}$ & -1.075 & 0.534 \\
\hline & 3 & $\mathbf{H}$ & -0.120 & -0.132 & -0.543 \\
\hline & 4 & $\mathbf{O}$ & 0.765 & -0.176 & -1.579 \\
\hline & 5 & $\mathbf{H}$ & 0.277 & 0.185 & -2.440 \\
\hline & 6 & $\mathbf{H}$ & 1.423 & 0.567 & -1.394 \\
\hline & 7 & $\mathbf{O}$ & -0.417 & 0.675 & -3.591 \\
\hline & 8 & $\mathbf{H}$ & -1.403 & 0.482 & -3.466 \\
\hline & 9 & $\mathbf{H}$ & -0.436 & 1.688 & -3.576 \\
\hline & 10 & $\mathbf{O}$ & 0.533 & 0.897 & 2.124 \\
\hline & 11 & $\mathbf{H}$ & -0.053 & 0.486 & 1.331 \\
\hline & 12 & $\mathbf{H}$ & -0.219 & 1.062 & 2.792 \\
\hline \multirow{12}{*}{$\mathrm{TS}_{1}$ Structure } & 1 & $\mathbf{O}$ & -0.792 & -0.298 & 0.541 \\
\hline & 2 & $\mathbf{H}$ & -0.442 & -1.247 & 0.500 \\
\hline & 3 & $\mathbf{H}$ & -0.369 & 0.083 & -0.333 \\
\hline & 4 & $\mathbf{O}$ & 0.300 & 0.661 & -1.527 \\
\hline & 5 & $\mathbf{H}$ & -0.358 & 1.272 & -1.999 \\
\hline & 6 & $\mathbf{H}$ & 0.968 & 1.345 & -1.193 \\
\hline & 7 & $\mathbf{O}$ & 0.003 & 0.647 & -4.132 \\
\hline & 8 & $\mathbf{H}$ & 0.806 & 1.086 & -4.577 \\
\hline & 9 & $\mathbf{H}$ & 0.500 & 0.173 & -3.378 \\
\hline & 10 & $\mathbf{O}$ & 0.655 & 0.820 & 2.305 \\
\hline & 11 & $\mathbf{H}$ & 0.043 & 0.349 & 1.597 \\
\hline & 12 & $\mathbf{H}$ & -0.051 & 0.977 & 3.021 \\
\hline \multirow{12}{*}{ Int 1 Structure } & 1 & $\mathbf{O}$ & -0.665 & -0.554 & 0.546 \\
\hline & 2 & $\mathbf{H}$ & -0.134 & -1.406 & 0.416 \\
\hline & 3 & $\mathbf{H}$ & -0.369 & -0.030 & -0.300 \\
\hline & 4 & $\mathbf{O}$ & 0.134 & 0.872 & -1.412 \\
\hline & 5 & $\mathbf{H}$ & -0.431 & 1.710 & -1.335 \\
\hline & 6 & $\mathbf{H}$ & 1.030 & 1.243 & -1.120 \\
\hline & 7 & $\mathbf{O}$ & 0.265 & 0.571 & -4.084 \\
\hline & 8 & $\mathbf{H}$ & 0.706 & -0.345 & -4.144 \\
\hline & 9 & $\mathbf{H}$ & 0.205 & 0.631 & -3.061 \\
\hline & 10 & $\mathbf{O}$ & 0.667 & 0.786 & 2.258 \\
\hline & 11 & $\mathbf{H}$ & 0.102 & 0.206 & 1.597 \\
\hline & 12 & $\mathbf{H}$ & -0.039 & 0.908 & 2.980 \\
\hline \multirow{12}{*}{$\mathrm{TS}_{2}$ Structure } & 1 & $\mathbf{O}$ & -0.193 & -0.511 & -0.111 \\
\hline & 2 & H & 0.560 & -0.594 & -0.793 \\
\hline & 3 & $\mathbf{H}$ & -0.564 & -1.454 & -0.151 \\
\hline & 4 & $\mathbf{O}$ & 0.202 & 0.486 & -2.402 \\
\hline & 5 & $\mathbf{H}$ & 0.569 & 1.430 & -2.366 \\
\hline & 6 & $\mathbf{H}$ & -0.550 & 0.567 & -1.720 \\
\hline & 7 & $\mathbf{O}$ & -0.951 & 0.212 & -4.749 \\
\hline & 8 & $\mathbf{H}$ & -0.508 & -0.663 & -5.022 \\
\hline & 9 & $\mathbf{H}$ & -0.490 & 0.322 & -3.832 \\
\hline & 10 & $\mathbf{O}$ & 0.957 & -0.239 & $\mathbf{2 . 2 3 7}$ \\
\hline & 11 & $\mathbf{H}$ & 0.496 & -0.350 & 1.319 \\
\hline & 12 & $\mathbf{H}$ & 0.515 & $\mathbf{0 . 6 3 7}$ & 2.508 \\
\hline \multirow{7}{*}{ Int $_{2}$ Structure } & 1 & $\mathbf{O}$ & -0.267 & -0.803 & -0.378 \\
\hline & 2 & $\mathbf{H}$ & 0.002 & -1.767 & -0.519 \\
\hline & 3 & $\mathbf{H}$ & -1.275 & -0.890 & -0.409 \\
\hline & 4 & $\mathbf{O}$ & 0.596 & 0.496 & -2.406 \\
\hline & 5 & $\mathbf{H}$ & 0.328 & 1.437 & -2.151 \\
\hline & 6 & $\mathbf{H}$ & 0.251 & -0.018 & -1.574 \\
\hline & 7 & $\mathbf{O}$ & -1.055 & -0.155 & -4.243 \\
\hline
\end{tabular}




\begin{tabular}{|c|c|c|c|c|c|}
\hline & 8 & $\mathbf{H}$ & -0.387 & -0.421 & -4.964 \\
\hline & 9 & H & -0.369 & 0.122 & -3.506 \\
\hline & 10 & $\mathbf{O}$ & 0.615 & -0.219 & 2.097 \\
\hline & 11 & $\mathbf{H}$ & 0.264 & -0.421 & 1.154 \\
\hline & 12 & $\mathbf{H}$ & 1.014 & 0.697 & 1.903 \\
\hline \multirow{12}{*}{$\mathrm{TS}_{3}$ Structure } & 1 & $\mathbf{O}$ & -0.475 & -0.549 & 1.812 \\
\hline & 2 & $\mathbf{H}$ & -1.067 & -1.316 & 1.515 \\
\hline & 3 & $\mathbf{H}$ & -1.177 & 0.156 & 2.015 \\
\hline & 4 & $\mathbf{O}$ & 0.832 & 0.129 & -0.243 \\
\hline & 5 & H & 0.852 & 1.135 & -0.126 \\
\hline & 6 & $\mathbf{H}$ & 0.338 & -0.145 & 0.634 \\
\hline & 7 & $\mathbf{O}$ & -1.042 & -0.274 & -1.908 \\
\hline & 8 & H & -0.523 & -0.758 & -2.637 \\
\hline & 9 & $\mathbf{H}$ & -0.243 & -0.097 & -1.253 \\
\hline & 10 & $\mathbf{O}$ & -0.745 & 0.498 & 4.183 \\
\hline & 11 & $\mathbf{H}$ & -0.195 & -0.194 & 3.673 \\
\hline & 12 & $\mathbf{H}$ & -1.266 & -0.144 & 4.776 \\
\hline \multirow{12}{*}{ End Structure } & 1 & $\mathbf{O}$ & -0.287 & -0.834 & 1.748 \\
\hline & 2 & $\mathbf{H}$ & -1.238 & -0.910 & 1.421 \\
\hline & 3 & $\mathbf{H}$ & -0.399 & -0.199 & 2.578 \\
\hline & 4 & $\mathbf{O}$ & 0.811 & 0.235 & -0.158 \\
\hline & 5 & H & 0.678 & 1.213 & 0.069 \\
\hline & 6 & H & 0.380 & -0.229 & 0.708 \\
\hline & 7 & $\mathbf{O}$ & -0.967 & -0.228 & -1.835 \\
\hline & 8 & $\mathbf{H}$ & -0.422 & -0.759 & -2.512 \\
\hline & 9 & H & -0.186 & -0.014 & -1.140 \\
\hline & 10 & O & -0.571 & 0.604 & 3.764 \\
\hline & 11 & H & -0.449 & -0.016 & 4.555 \\
\hline & 12 & H & -1.551 & 0.840 & 3.874 \\
\hline
\end{tabular}


Table S5. The coordinates of the CNT.

\begin{tabular}{|c|c|c|c|c|c|}
\hline CNT Structure & Number & Atom & $\mathrm{x}(\AA)$ & $\mathrm{y}(\AA)$ & $z(\AA)$ \\
\hline & 7 & $\mathrm{C}$ & 0.292 & 4.079 & 7.385 \\
\hline & 8 & $\mathrm{C}$ & -0.420 & 4.115 & 8.606 \\
\hline & 9 & $\mathrm{C}$ & 0.354 & 4.194 & 9.802 \\
\hline & 10 & $\mathrm{C}$ & 0.300 & 4.081 & 2.461 \\
\hline & 11 & $\mathrm{C}$ & -0.415 & 4.076 & 3.690 \\
\hline & 12 & $\mathrm{C}$ & 0.297 & 4.078 & 4.914 \\
\hline & 13 & $\mathrm{C}$ & -1.773 & 3.668 & 6.148 \\
\hline & 14 & $\mathrm{C}$ & -0.418 & 4.052 & 6.148 \\
\hline & 15 & $\mathrm{C}$ & -2.391 & 3.318 & 7.385 \\
\hline & 16 & $\mathrm{C}$ & -1.803 & 3.722 & 8.606 \\
\hline & 17 & $\mathrm{C}$ & -3.457 & 2.404 & 9.802 \\
\hline & 18 & $\mathrm{C}$ & -2.503 & 3.384 & 9.802 \\
\hline & 19 & $\mathrm{C}$ & 0.300 & 4.081 & -2.461 \\
\hline & 20 & $\mathrm{C}$ & -0.418 & 4.071 & -1.227 \\
\hline & 21 & $\mathrm{C}$ & 0.297 & 4.089 & 0.001 \\
\hline & 22 & $\mathrm{C}$ & -1.782 & 3.684 & 1.227 \\
\hline & 23 & $\mathrm{C}$ & -0.418 & 4.071 & 1.226 \\
\hline & 24 & $\mathrm{C}$ & -2.398 & 3.315 & 2.461 \\
\hline & 25 & $\mathrm{C}$ & -1.787 & 3.687 & 3.690 \\
\hline & 26 & $\mathrm{C}$ & -3.385 & 2.297 & 4.914 \\
\hline & 27 & $\mathrm{C}$ & -2.395 & 3.315 & 4.914 \\
\hline & 28 & $\mathrm{C}$ & -3.721 & 1.665 & 6.148 \\
\hline & 29 & $\mathrm{C}$ & -3.389 & 2.293 & 7.385 \\
\hline & 30 & $\mathrm{C}$ & -4.126 & 0.300 & 8.606 \\
\hline & 31 & $\mathrm{C}$ & -3.776 & 1.695 & 8.606 \\
\hline & 32 & $\mathrm{C}$ & -4.180 & -0.475 & 9.803 \\
\hline & 33 & $\mathrm{C}$ & 0.292 & 4.079 & -7.385 \\
\hline & 34 & $\mathrm{C}$ & -0.418 & 4.052 & -6.148 \\
\hline & 35 & $\mathrm{C}$ & 0.297 & 4.078 & -4.914 \\
\hline & 36 & $\mathrm{C}$ & -1.787 & 3.687 & -3.690 \\
\hline & 37 & $\mathrm{C}$ & -0.415 & 4.076 & -3.690 \\
\hline & 38 & $\mathrm{C}$ & -2.398 & 3.315 & -2.461 \\
\hline & 39 & $\mathrm{C}$ & -1.782 & 3.684 & -1.227 \\
\hline & 40 & $\mathrm{C}$ & -3.395 & 2.302 & 0.000 \\
\hline & 41 & $\mathrm{C}$ & -2.399 & 3.324 & -0.000 \\
\hline & 42 & $\mathrm{C}$ & -3.738 & 1.675 & 1.227 \\
\hline & 43 & $\mathrm{C}$ & -3.386 & 2.300 & 2.461 \\
\hline & 44 & $\mathrm{C}$ & -4.088 & 0.296 & 3.690 \\
\hline & 45 & $\mathrm{C}$ & -3.740 & 1.680 & 3.690 \\
\hline & 46 & $\mathrm{C}$ & -4.068 & -0.416 & 4.914 \\
\hline & 47 & $\mathrm{C}$ & -4.064 & 0.299 & 6.148 \\
\hline & 48 & $\mathrm{C}$ & -3.678 & -1.787 & 7.385 \\
\hline & 49 & $\mathrm{C}$ & -4.069 & -0.411 & 7.385 \\
\hline & 50 & $\mathrm{C}$ & -3.354 & -2.422 & 8.606 \\
\hline & 51 & $\mathrm{C}$ & -3.807 & -1.791 & 9.803 \\
\hline & 52 & $\mathrm{C}$ & 0.353 & 4.194 & -9.802 \\
\hline & 53 & $\mathrm{C}$ & -1.803 & 3.723 & -8.606 \\
\hline & 54 & $\mathrm{C}$ & -0.420 & 4.115 & -8.606 \\
\hline & 55 & $\mathrm{C}$ & -2.391 & 3.318 & -7.385 \\
\hline & 56 & $\mathrm{C}$ & -1.773 & 3.668 & -6.148 \\
\hline & 57 & $\mathrm{C}$ & -3.385 & 2.297 & -4.914 \\
\hline & 58 & $\mathrm{C}$ & -2.395 & 3.315 & -4.914 \\
\hline & 59 & $\mathrm{C}$ & -3.741 & 1.680 & -3.690 \\
\hline & 60 & $\mathrm{C}$ & -3.386 & 2.300 & -2.461 \\
\hline & 61 & $\mathrm{C}$ & -4.083 & 0.299 & -1.226 \\
\hline & 62 & $\mathrm{C}$ & -3.738 & 1.675 & -1.226 \\
\hline & 63 & $\mathrm{C}$ & -4.079 & -0.415 & 0.000 \\
\hline \multicolumn{6}{|c|}{$\mathrm{S} 16$} \\
\hline
\end{tabular}




\begin{tabular}{|c|c|c|c|c|}
\hline 64 & $\mathrm{C}$ & -4.083 & 0.299 & 1.227 \\
\hline 65 & $\mathrm{C}$ & -3.684 & -1.781 & 2.461 \\
\hline 66 & $\mathrm{C}$ & -4.070 & -0.419 & 2.461 \\
\hline 67 & $\mathrm{C}$ & -3.324 & -2.399 & 3.690 \\
\hline 68 & $\mathrm{C}$ & -3.680 & -1.782 & 4.914 \\
\hline 69 & $\mathrm{C}$ & -2.292 & -3.371 & 6.148 \\
\hline 70 & $\mathrm{C}$ & -3.302 & -2.389 & 6.148 \\
\hline 71 & $\mathrm{C}$ & -1.679 & -3.731 & 7.385 \\
\hline 72 & $\mathrm{C}$ & -2.324 & -3.425 & 8.606 \\
\hline 73 & $\mathrm{C}$ & -0.353 & -4.194 & 9.802 \\
\hline 74 & $\mathrm{C}$ & -1.679 & -3.861 & 9.802 \\
\hline 75 & $\mathrm{C}$ & -3.457 & 2.404 & -9.802 \\
\hline 76 & $\mathrm{C}$ & -2.503 & 3.384 & -9.802 \\
\hline 77 & $\mathrm{C}$ & -3.776 & 1.695 & -8.606 \\
\hline 78 & $\mathrm{C}$ & -3.389 & 2.293 & -7.385 \\
\hline 79 & $\mathrm{C}$ & -4.065 & 0.299 & -6.148 \\
\hline 80 & $\mathrm{C}$ & -3.721 & 1.665 & -6.148 \\
\hline 81 & $\mathrm{C}$ & -4.068 & -0.416 & -4.914 \\
\hline 82 & $\mathrm{C}$ & -4.088 & 0.296 & -3.690 \\
\hline 83 & $\mathrm{C}$ & -3.684 & -1.781 & -2.461 \\
\hline 84 & $\mathrm{C}$ & -4.070 & -0.419 & -2.461 \\
\hline 85 & $\mathrm{C}$ & -3.318 & -2.398 & -1.227 \\
\hline 86 & $\mathrm{C}$ & -3.689 & -1.788 & 0.000 \\
\hline 87 & $\mathrm{C}$ & -2.301 & -3.388 & 1.227 \\
\hline 88 & $\mathrm{C}$ & -3.318 & -2.398 & 1.227 \\
\hline 89 & $\mathrm{C}$ & -1.673 & -3.736 & 2.461 \\
\hline 90 & $\mathrm{C}$ & -2.301 & -3.394 & 3.690 \\
\hline 91 & $\mathrm{C}$ & -0.297 & -4.078 & 4.914 \\
\hline 92 & $\mathrm{C}$ & -1.675 & -3.733 & 4.914 \\
\hline 93 & $\mathrm{C}$ & 0.418 & -4.052 & 6.148 \\
\hline 94 & $\mathrm{C}$ & -0.292 & -4.079 & 7.385 \\
\hline 95 & $\mathrm{C}$ & 1.803 & -3.723 & 8.606 \\
\hline 96 & $\mathrm{C}$ & 0.420 & -4.115 & 8.606 \\
\hline 97 & $\mathrm{C}$ & 2.503 & -3.384 & 9.802 \\
\hline 98 & $\mathrm{C}$ & -4.180 & -0.475 & -9.803 \\
\hline 99 & $\mathrm{C}$ & -4.127 & 0.300 & -8.606 \\
\hline 100 & $\mathrm{C}$ & -3.679 & -1.787 & -7.385 \\
\hline 101 & $\mathrm{C}$ & -4.069 & -0.411 & -7.385 \\
\hline 102 & $\mathrm{C}$ & -3.302 & -2.389 & -6.148 \\
\hline 103 & $\mathrm{C}$ & -3.680 & -1.782 & -4.914 \\
\hline 104 & $\mathrm{C}$ & -2.301 & -3.394 & -3.690 \\
\hline 105 & $\mathrm{C}$ & -3.324 & -2.399 & -3.690 \\
\hline 106 & $\mathrm{C}$ & -1.673 & -3.736 & -2.461 \\
\hline 107 & $\mathrm{C}$ & -2.301 & -3.388 & -1.227 \\
\hline 108 & $\mathrm{C}$ & -0.296 & -4.089 & -0.000 \\
\hline 109 & $\mathrm{C}$ & -1.681 & -3.742 & 0.000 \\
\hline 110 & $\mathrm{C}$ & 0.418 & -4.071 & 1.226 \\
\hline 111 & $\mathrm{C}$ & -0.300 & -4.080 & 2.461 \\
\hline 112 & $\mathrm{C}$ & 1.787 & -3.687 & 3.690 \\
\hline 113 & $\mathrm{C}$ & 0.415 & -4.076 & 3.690 \\
\hline 114 & $\mathrm{C}$ & 2.395 & -3.315 & 4.914 \\
\hline 115 & $\mathrm{C}$ & 1.773 & -3.668 & 6.148 \\
\hline 116 & $\mathrm{C}$ & 3.389 & -2.293 & 7.385 \\
\hline 117 & $\mathrm{C}$ & 2.391 & -3.318 & 7.385 \\
\hline 118 & $\mathrm{C}$ & 3.776 & -1.695 & 8.606 \\
\hline 119 & $\mathrm{C}$ & 3.457 & -2.404 & 9.802 \\
\hline 120 & $\mathrm{C}$ & -3.807 & -1.790 & -9.803 \\
\hline 121 & $\mathrm{C}$ & -2.324 & -3.425 & -8.606 \\
\hline 122 & $\mathrm{C}$ & -3.354 & -2.422 & -8.606 \\
\hline 123 & $\mathrm{C}$ & -1.680 & -3.731 & -7.385 \\
\hline
\end{tabular}




\begin{tabular}{|c|c|c|c|c|}
\hline 124 & $\mathrm{C}$ & -2.292 & -3.371 & -6.148 \\
\hline 125 & $\mathrm{C}$ & -0.297 & -4.078 & -4.914 \\
\hline 126 & $\mathrm{C}$ & -1.675 & -3.733 & -4.914 \\
\hline 127 & $\mathrm{C}$ & 0.415 & -4.076 & -3.690 \\
\hline 128 & $\mathrm{C}$ & -0.300 & -4.080 & -2.461 \\
\hline 129 & $\mathrm{C}$ & 1.782 & -3.684 & -1.227 \\
\hline 130 & $\mathrm{C}$ & 0.418 & -4.071 & -1.227 \\
\hline 131 & $\mathrm{C}$ & 2.399 & -3.324 & -0.000 \\
\hline 132 & $\mathrm{C}$ & 1.783 & -3.684 & 1.226 \\
\hline 133 & $\mathrm{C}$ & 3.386 & -2.301 & 2.461 \\
\hline 134 & $\mathrm{C}$ & 2.398 & -3.315 & 2.461 \\
\hline 135 & $\mathrm{C}$ & 3.741 & -1.680 & 3.690 \\
\hline 136 & $\mathrm{C}$ & 3.385 & -2.297 & 4.914 \\
\hline 137 & $\mathrm{C}$ & 4.065 & -0.299 & 6.148 \\
\hline 138 & $\mathrm{C}$ & 3.721 & -1.665 & 6.148 \\
\hline 139 & $\mathrm{C}$ & 4.069 & 0.411 & 7.385 \\
\hline 140 & $\mathrm{C}$ & 4.127 & -0.300 & 8.606 \\
\hline 141 & $\mathrm{C}$ & 3.807 & 1.790 & 9.803 \\
\hline 142 & $\mathrm{C}$ & 4.180 & 0.475 & 9.803 \\
\hline 143 & $\mathrm{C}$ & -0.354 & -4.194 & -9.802 \\
\hline 144 & $\mathrm{C}$ & -1.679 & -3.861 & -9.802 \\
\hline 145 & $\mathrm{C}$ & 0.420 & -4.115 & -8.606 \\
\hline 146 & $\mathrm{C}$ & -0.292 & -4.079 & -7.385 \\
\hline 147 & $\mathrm{C}$ & 1.773 & -3.668 & -6.148 \\
\hline 148 & $\mathrm{C}$ & 0.418 & -4.052 & -6.148 \\
\hline 149 & $\mathrm{C}$ & 2.395 & -3.315 & -4.914 \\
\hline 150 & $\mathrm{C}$ & 1.787 & -3.687 & -3.690 \\
\hline 151 & $\mathrm{C}$ & 3.386 & -2.300 & -2.461 \\
\hline 152 & $\mathrm{C}$ & 2.398 & -3.315 & -2.461 \\
\hline 153 & $\mathrm{C}$ & 3.738 & -1.675 & -1.227 \\
\hline 154 & $\mathrm{C}$ & 3.395 & -2.302 & -0.000 \\
\hline 155 & $\mathrm{C}$ & 4.083 & -0.299 & 1.227 \\
\hline 156 & $\mathrm{C}$ & 3.738 & -1.675 & 1.226 \\
\hline 157 & $\mathrm{C}$ & 4.070 & 0.419 & 2.461 \\
\hline 158 & $\mathrm{C}$ & 4.088 & -0.296 & 3.690 \\
\hline 159 & $\mathrm{C}$ & 3.680 & 1.782 & 4.914 \\
\hline 160 & $\mathrm{C}$ & 4.068 & 0.416 & 4.914 \\
\hline 161 & $\mathrm{C}$ & 3.302 & 2.389 & 6.148 \\
\hline 162 & $\mathrm{C}$ & 3.679 & 1.787 & 7.385 \\
\hline 163 & $\mathrm{C}$ & 2.324 & 3.425 & 8.606 \\
\hline 164 & $\mathrm{C}$ & 3.354 & 2.422 & 8.606 \\
\hline 165 & $\mathrm{C}$ & 1.679 & 3.861 & 9.802 \\
\hline 166 & $\mathrm{C}$ & 2.503 & -3.384 & -9.802 \\
\hline 167 & $\mathrm{C}$ & 1.803 & -3.722 & -8.606 \\
\hline 168 & $\mathrm{C}$ & 3.389 & -2.293 & -7.385 \\
\hline 169 & $\mathrm{C}$ & 2.391 & -3.318 & -7.385 \\
\hline 170 & $\mathrm{C}$ & 3.721 & -1.665 & -6.148 \\
\hline 171 & $\mathrm{C}$ & 3.385 & -2.297 & -4.914 \\
\hline 172 & $\mathrm{C}$ & 4.088 & -0.296 & -3.690 \\
\hline 173 & $\mathrm{C}$ & 3.740 & -1.680 & -3.690 \\
\hline 174 & $\mathrm{C}$ & 4.070 & 0.419 & -2.461 \\
\hline 175 & $\mathrm{C}$ & 4.083 & -0.299 & -1.227 \\
\hline 176 & $\mathrm{C}$ & 3.689 & 1.788 & -0.000 \\
\hline 177 & $\mathrm{C}$ & 4.079 & 0.415 & -0.000 \\
\hline 178 & $\mathrm{C}$ & 3.318 & 2.398 & 1.227 \\
\hline 179 & $\mathrm{C}$ & 3.684 & 1.781 & 2.461 \\
\hline 180 & $\mathrm{C}$ & 2.301 & 3.394 & 3.690 \\
\hline 181 & $\mathrm{C}$ & 3.324 & 2.399 & 3.690 \\
\hline 182 & $\mathrm{C}$ & 1.675 & 3.733 & 4.914 \\
\hline 183 & $\mathrm{C}$ & 2.292 & 3.371 & 6.148 \\
\hline
\end{tabular}




\begin{tabular}{lrrrr}
184 & C & 1.680 & 3.731 & 7.385 \\
185 & $\mathrm{C}$ & 3.457 & -2.404 & -9.802 \\
186 & $\mathrm{C}$ & 4.127 & -0.300 & -8.606 \\
187 & $\mathrm{C}$ & 3.776 & -1.695 & -8.606 \\
188 & $\mathrm{C}$ & 4.069 & 0.411 & -7.385 \\
189 & $\mathrm{C}$ & 4.064 & -0.299 & -6.148 \\
190 & $\mathrm{C}$ & 3.680 & 1.782 & -4.914 \\
191 & $\mathrm{C}$ & 4.068 & 0.416 & -4.914 \\
192 & $\mathrm{C}$ & 3.324 & 2.399 & -3.690 \\
193 & $\mathrm{C}$ & 3.683 & 1.781 & -2.461 \\
194 & $\mathrm{C}$ & 2.301 & 3.388 & -1.227 \\
195 & $\mathrm{C}$ & 3.318 & 2.398 & -1.227 \\
196 & $\mathrm{C}$ & 1.680 & 3.742 & -0.000 \\
197 & $\mathrm{C}$ & 2.302 & 3.388 & 1.226 \\
198 & $\mathrm{C}$ & 1.673 & 3.736 & 2.461 \\
199 & $\mathrm{C}$ & 3.807 & 1.791 & -9.803 \\
200 & $\mathrm{C}$ & 4.180 & 0.475 & -9.803 \\
201 & $\mathrm{C}$ & 3.354 & 2.422 & -8.606 \\
202 & $\mathrm{C}$ & 3.678 & 1.787 & -7.385 \\
203 & $\mathrm{C}$ & 2.292 & 3.371 & -6.148 \\
204 & $\mathrm{C}$ & 3.302 & 2.389 & -6.148 \\
205 & $\mathrm{C}$ & 1.675 & 3.733 & -4.914 \\
206 & $\mathrm{C}$ & 2.301 & 3.394 & -3.690 \\
207 & $\mathrm{C}$ & 1.673 & 3.736 & -2.461 \\
208 & $\mathrm{C}$ & 1.679 & 3.861 & -9.802 \\
209 & $\mathrm{C}$ & 2.324 & 3.425 & -8.606 \\
210 & $\mathrm{C}$ & 1.680 & 3.731 & -7.385 \\
211 & $\mathrm{H}$ & -0.135 & 4.401 & 10.749 \\
212 & $\mathrm{H}$ & -3.881 & 2.085 & 10.749 \\
213 & $\mathrm{H}$ & -2.196 & 3.816 & 10.749 \\
214 & $\mathrm{H}$ & -4.399 & 0.007 & 10.750 \\
215 & $\mathrm{H}$ & -3.740 & -2.317 & 10.750 \\
216 & $\mathrm{H}$ & -0.135 & 4.401 & -10.749 \\
217 & $\mathrm{H}$ & 0.135 & -4.401 & 10.749 \\
218 & $\mathrm{H}$ & -2.208 & -3.812 & 10.749 \\
219 & $\mathrm{H}$ & -3.881 & 2.085 & -10.749 \\
220 & $\mathrm{H}$ & -2.196 & 3.817 & -10.749 \\
221 & $\mathrm{H}$ & 2.196 & -3.817 & 10.749 \\
222 & $\mathrm{H}$ & -4.400 & 0.008 & -10.749 \\
223 & $\mathrm{H}$ & 3.881 & -2.085 & 10.749 \\
224 & $\mathrm{H}$ & -3.740 & -2.317 & -10.750 \\
225 & $\mathrm{H}$ & 3.740 & 2.317 & 10.750 \\
226 & $\mathrm{H}$ & 4.400 & -0.008 & 10.750 \\
227 & $\mathrm{H}$ & 0.135 & -4.401 & -10.749 \\
228 & $\mathrm{H}$ & -2.208 & -3.812 & -10.749 \\
229 & $\mathrm{H}$ & 2.208 & 3.812 & 10.749 \\
230 & $\mathrm{H}$ & 2.196 & -3.816 & -10.749 \\
231 & $\mathrm{H}$ & 3.881 & -2.085 & -10.749 \\
232 & $\mathrm{H}$ & 3.740 & 2.317 & -10.750 \\
233 & $\mathrm{H}$ & 4.399 & -0.007 & -10.750 \\
234 & $\mathrm{H}$ & 2.208 & 3.812 & -10.749 \\
\hline & & & & \\
& & & &
\end{tabular}




\section{References}

1. Hammond, J. R. ; Govind, N. ; Kowalski, K. ; Autschbach, J. ; Xantheas, S. S. Accurate dipole polarizabilities for water clusters $n=2-12$ at the coupled-cluster level of theory and benchmarking of various density functionals. J. Chem. Phys. 2009, 131 (21), 214103.

2. Santra, B. ; Michaelides, A. ; Scheffler, M. On the accuracy of density-functional theory exchange-correlation functionals for $H$ bonds in small water clusters: Benchmarks approaching the complete basis set limit. J. Chem. Phys. 2007, 127 (18). 3. Wellington, J. P. W. ; Tegner, B. E. ; Collard, J. ; Kerridge, A. ; Kaltsoyannis, N. 0xygen Vacancy Formation and Water Adsorption on Reduced An02\{111\}, \{110\}, and $\{100\}$ Surfaces (An = U, Pu): A Computational Study. J. Phys. Chem. C 2018, 122 (13), 71497165 .

4. Lousada, C. M. ; Johansson, A. J. ; Brinck, T. ; Jonsson, M. Reactivity of metal oxide clusters with hydrogen peroxide and water - a DFT study evaluating the performance of different exchange-correlation functionals. Phys. Chem. Chem. Phys. 2013, 15 (15), 5539-5552.

5. Zhang, C. ; Donadio, D. ; Gygi, F. ; Galli, G. First Principles Simulations of the Infrared Spectrum of Liquid Water Using Hybrid Density Functionals. J. Chem. Theory Comput. 2011, 7 (5), 1443-1449.

6. Hummer, G. ; Rasaiah, J. C. ; Noworyta, J. P. Water conduction through the hydrophobic channel of a carbon nanotube. Nature 2001, 414 (6860), 188-190.

7. Zhou, R. ; Huang, X. ; Margulis, C. J. ; Berne, B. J. Hydrophobic Collapse in Multidomain Protein Folding. Science 2004, 305 (5690), 1605.

8. Wang, C. ; Lu, H. ; Wang, Z. ; Xiu, P. ; Zhou, B. ; Zuo, G. ; Wan, R. ; Hu, J. ; Fang, H. Stable Liquid Water Droplet on a Water Monolayer Formed at Room Temperature on Ionic Model Substrates. Phys. Rev. Lett. 2009, 103 (13), 137801.

9. van der Spoe1, D. ; van Maaren, P. J. ; Berendsen, H. J. C. A systematic study of water models for molecular simulation: Derivation of water models optimized for use with a reaction field. J. Chem. Phys. 1998, 108 (24), 10220-10230.

10. Wan, R. Z. ; Li, J. Y. ; Lu, H. J. ; Fang, H. P. Controllable water channel gating of nanometer dimensions. J. Am. Chem. Soc. 2005, 127 (19), 7166-7170.

11. Alexiadis, A. ; Kassinos, S. Molecular Simulation of Water in Carbon Nanotubes. Chem. Rev. 2008, 108 (12), 5014-5034.

12. Sam, A. ; Prasad, K. V. ; Sathian, S. P. Water flow in carbon nanotubes: the role of tube chirality. Phys. Chem. Chem. Phys. 2019, 21 (12), 6566-6573.

13. Feng, J.-w. ; Ding, H. -m. ; Ren, C. -1 . ; Ma, Y. -q. Pumping of water by rotating chiral carbon nanotube. Nanoscale 2014, 6 (22), 13606-13612.

14. Zhang, W. W. ; Chen, X. ; van Duin, A. C. T. Isotope Effects in Water: Differences of Structure, Dynamics, Spectrum, and Proton Transport between Heavy and Light Water from ReaxFF Reactive Force Field Simulations. J. Phys. Chem. Lett. 2018, 9 (18), 5445-5452.

15. Dahal, U. ; Adhikari, N. P. Molecular dynamics study of diffusion of heavy water in normal water at different temperatures. J. Mol. Liq. 2012, 167, 34-39. 